\title{
DESIGNING STRUCTURAL JOLNTS ACCORDHNG TO EUROCODES
}

\author{
J.P. JASPART \\ Department MSM, University of Liège, \\ 1, Chemin des Chevreuils, B-4000 Liège 1, Belgium.
}

\section{Introduction}

In Eurocode 3 [1] on steel buildings, the design of structural joints is covered by Chapter 6 and, for joints between $\mathrm{H}$ or I profiles, by Annex J. During the recent revision of Annex J [2], a new comprehensive design approach for the design of joints has been implemented and the so-called "component method" has been introduced as a basic procedure for the derivation of the stiffness and strength properties of the structural joints, whatever is the joint configuration (single-sided or double-sided beam-to-column joints, beam splices, ...) and the connection type (welded connections, bolted connections with end-plates, flange cleats, ...). More recently, the application of the component method has been extended to base plates configurations [3] and composite steel-concrete joints [4].

In the present paper, the new design approach suggested by Eurocode 3 is presented and the advantages that the component method offers in comparison with traditional design approaches are illustrated by describing or referring to practical situations where economic and safe solutions have been made possible.

\section{The concept of joint representation}

During many years, the research activity in the field of joints mainly concentrated on two aspects:

- the evaluation of the mechanical properties of the joints in terms of rotational stiffness, moment resistance and rotation capacity;

- the analysis and design procedures for frames including joint behaviour.

But progressively it has been understood that there were intermediate steps to consider in order to integrate in a consistent way the actual joint response into the frame analysis; this is known as the joint representation.

The joint representationsincludes four successive steps respectively named:

- the joint characterisation

i.e. the evaluation through appropriate means of the stiffness, resistance and ductility properties of the joints (full $M-\varphi$ curves or key values);

- the joint modelling

i.e. the way on how the joint is physically represented in view of the frame analysis;

C.C. Baniotopoulos and F. Wald (eds.), The Paramount Role of Joints into the Reliable Response of Structures, 349-362. (c) 2000 Kluwer Academic Publishers. Printed in the Netherlands. 
- the joint classification

i.e. the tool providing boundary conditions for the use of conventional types of joint modelling (e.g. rigid or pinned);

- the joint idealisation

i.e. the derivation of a simplified moment-rotation curve so as to fit with specific analysis approaches (e.g. linear idealisation for an elastic analysis).

These four items are discussed in the next pages.

\subsection{JOINT CHARACTERISATION}

The procedure adopted in Revised Annex $\mathrm{J}$ for the characterisation of mechanical properties of the structural joints is based on the "component method".

Roughly speaking this one may be presented as the application of the well-known finite element method to the calculation of structural joints.

In the characterisation procedures, a joint is generally considered as a whole and is studied accordingly; the originality of the component method is to consider any joint as a set of "individual basic components". In the particular case of Figure 1 (single-sided beam-to-column joint with an extended end-plate connection subject to bending), the relevant components are the following:

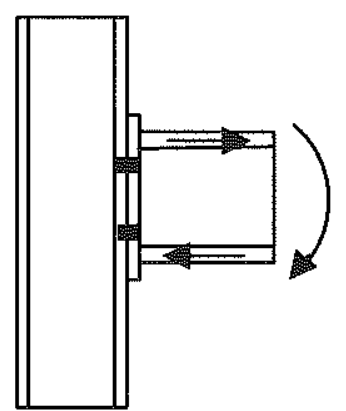

Figure 1. Joint with end-plate in bending
- compression zone :

- column web in compression

- beam flange and web in compression

- in shear zone :

- column web panel in shear

- tension zone :

- beam web in tension

- column web in tension

- column flange in bending

- bolts in tension

- end-plate in bending

Each of these basic components possesses its own level of strength and stiffness in tension, compression or shear. The coexistence of several components within the same joint element - for instance, the column web which is simultaneously subjected to compression (or tension) and shear - can obviously lead to stress interactions that are likely to decrease the strength of each individual basic component [5]; this interaction affects the shape of the deformability curve of the related components but does not call the principles of the component method in question again.

The application of the component method requires the following steps :

a) identification of the active components for the studied joint;

b) evaluation of the mechanical characteristics of each individual basic component (specific characteristics - initial stiffness, design strength, ... - or the whole deformability curve); 
c) "assembly" of the components in view of the evaluation of the mechanical characteristics of the whole joint (specific characteristics - initial stiffness, design resistance, .... - or the whole deformability $M$ - $\varphi$ curve).

These three steps are schematically illustrated in Figure 2 in the particular and simple case of a beam-to-column steel joint with a welded connection.

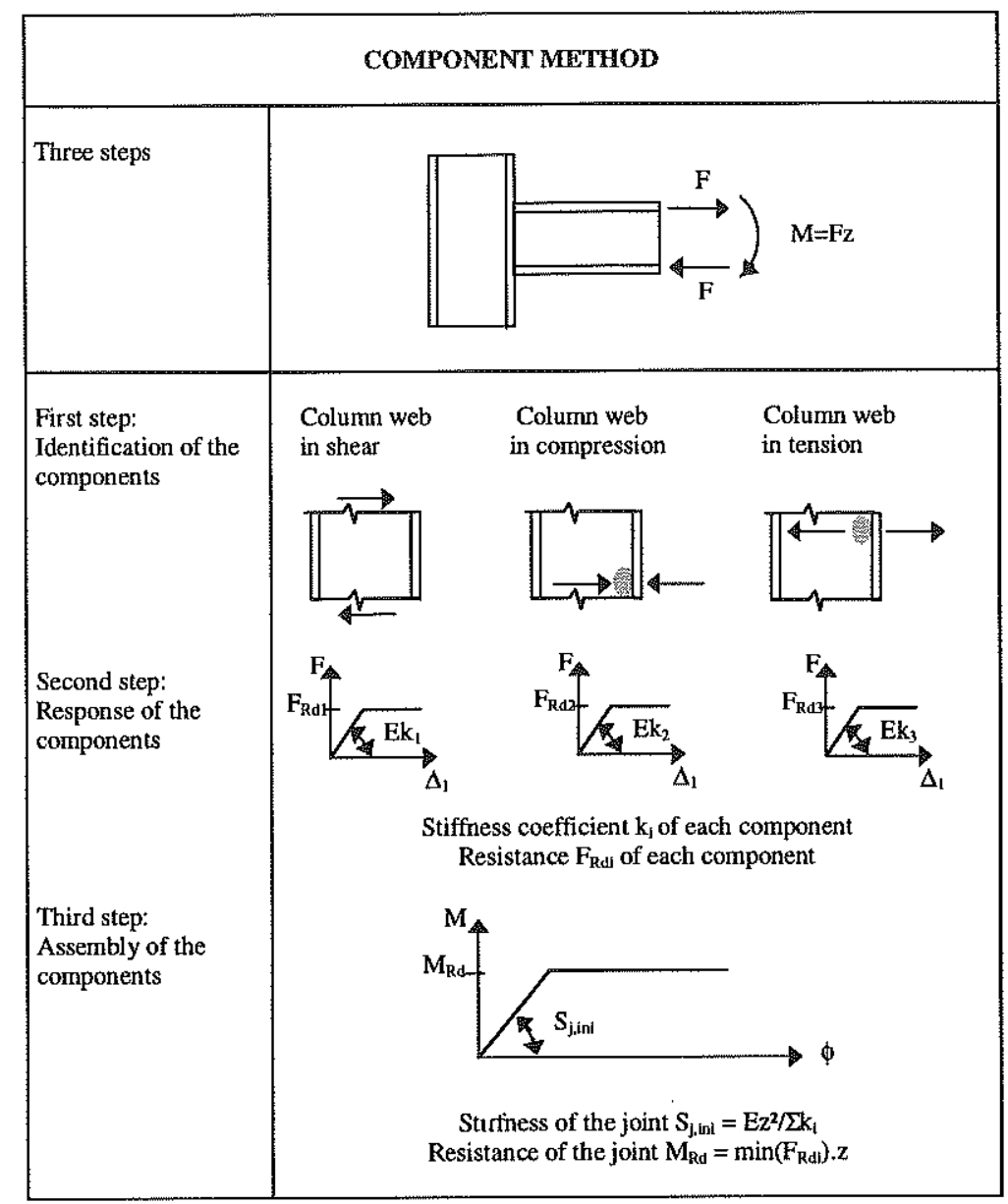

Figure 2. Application of the component method to a welded steel joint (simplified bi-linear component and joint deformability curves)

The assembly is based on a distribution of the internal forces within the joint. As a matter of fact, the external loads applied to the joint distribute, at each loading step, between the individual components according to the instantaneous stiffness and resistance of each component. Distributions of internal forces may be obtained through different ways as discussed in [5].

The application of the component method requires a sufficient knowledge of the behaviour of the basic components. To review all the publications devoted to this 
subject would be quite long and therefore references are made here to recent synthesis documents.

The components active in the traditional steel joints have been deeply studied and recommendations for their characterisation are given in the Revised Annex $J$ of Eurocode 3 . The combination of these components allows to cover a wide range of joint configurations, what should largely be sufficient to satisfy the needs of practitioners as far as beam-to-column joints and beam splices in bending are concerned. The application is however limited to joints between $\mathrm{H}$ or I hot-rolled profiles or built-up ones with similar dimensions.

But some new fields of application have been recently investigated :

- Weak axis joints where the beam is connected to the web of a $\mathrm{H}$ or I column profile [5];

- Joints between I beam profiles and tubular columns [8];

- Joints subject to bending moment (and shear) and axial compression or tension forces [5];

- Column bases [3];

- Stell-concrete composite joints [4];

- Steel joints with beam haunches, end-plate stiffeners or high strength steels [5];

- Joints in pitched-roof portal frames where beams and columns form an angle higher than $90^{\circ}[5]$;

- Joints between slender built-up welded profiles [5].

Preliminary works also indicate that the component method seems also suitable for the characterisation of joints subjected to extreme loading conditions as earthquakes or fire. Besides that, first attempts have been made in the COST C1 European Action on "Control of the Semi-Rigid Behaviour of Civil Engineering Connections" (1992-1996) to apply the component method to joints in pre-cast and timber construction. So it may reasonably be thought nowadays that an unified characterisation procedure for all structural joints is now developing and will be the common basis for the future design codes whatever is the material or the combination of materials used. This is likely to lighten the work of the designers, in particular when composite construction is of concern (the composite action between the materials is or not effective according to the erection stages).

The framework of the component method is sufficiently general to allow the use of various techniques of component characterisation and joint assembly. In particular, the stiffness and strength characteristics of the components may result from experimentations in laboratory, numerical simulations by means of finite element programs or analytical models based on theory. Often experimentation and numerical simulations are used as references when developing and validating analytical models. The latter may be developed with different levels of sophistication:

- expressions as those presented in $\mathrm{PhD}$ theses cover the influence of all the parameters which affect significantly the component behaviour (strain hardening, bolt head and nut dimensions, bolt prestressing, ...) from the beginning of the loading to collapse (plasticity, instability, ...);

- rules such as those which have been introduced in the Revised Annex J of Eurocode 3 are more simple and therefore more suitable for hand calculations; 
- as an ultimate step in the simplification process, simplified calculation procedures and design tables for standardised joints or components have been produced [6]; they allow a quick and nevertheless accurate prediction of the main joint properties. Besides that, design software for joints are also available on the market.

Similar levels of sophistication exist also for what regards the joint assembly.

\subsection{JOINT MODELLING}

Joint behaviour affects the structural frame response and shall therefore be modelled, just as for beams and columns, for the frame analysis and design. Traditionally, the following types of joint modelling are considered :

For rotational stiffness :

- rigid

- pinned
For resistance :

- full-strength

- partial-strength

- pinned

When the joint rotational stiffness is of concern, the wording rigid means that no relative rotation occurs between the connected members whatever is the applied moment. The wording pinned postulates the existence of a perfect (i.e. frictionless) hinge between the members. In fact these definitions may be relaxed. Indeed rather flexible but not fully pinned joints and rather stiff but not fully rigid joints may be considered respectively as effectively pinned and perfectly rigid. The stiffness boundaries allowing one to classify joints as rigid or pinned are discussed in the next section.

For joint resistance, a full-strength joint is stronger than the weaker of the connected members, which is in contrast to a partial-strength joint. In the everyday practice, partial-strength joints are used whenever the joints are designed to transfer the internal forces but not to resist the full capacity of the connected members. A pinned joint is considered to transfer only a limited moment. Related classification criteria are also expressed in the next section.

Consideration of rotational stiffness and joint resistance properties leads traditionally to three significant joint models: rigid/full-strength, rigid/partial-strength and pinned.

However, as far as the joint rotational stiffness is considered, joints designed for economy may be neither rigid nor pinned but semi-rigid. There are thus new possibilities for joint modelling: semi-rigid/full-strength and semi-rigid/partial-strength.

With a view to simplification, Eurocode 3 accounts for these possibilities by introducing three joint models (Table 1) :

- continuous: covering the rigid/full-strength case only;

- semi-continuous: covering the rigid/partial-strength, semi-rigid/full-strength and semi-rigid/partial-strength cases;

- simple : covering the pinned case only.

The following meanings are given to these terms :

- continuous: the joint ensures a full rotational continuity between the connected members; 
- semi-continuous: the joint ensures only a partial rotational continuity between the connected members;

- simple: the joint prevents from any rotational continuity between the connected members;

Table 1. Types of joint modelling

\begin{tabular}{|l|c|c|c|}
\hline \multirow{2}{*}{ STIFFNESS } & \multicolumn{3}{|c|}{ RESISTANCE } \\
\cline { 2 - 4 } & Full-strength & Partial-strength & Pinned \\
\hline Rigid & Continuous & Semi-continuous & $*$ \\
\hline Semi-rigid & Semi-continuous & Semi-continuous & $*$ \\
\hline Pinned & $*$ & $*$ & Simple \\
\hline \multicolumn{4}{|c|}{$*$ Without meaning } \\
\hline
\end{tabular}

Table 2. Joint modelling and frame analysis

\begin{tabular}{|l|l|l|l|}
\hline \multirow{2}{*}{ MODELLING } & \multicolumn{3}{|c|}{ TYPE OF FRAME ANALYSIS } \\
\cline { 2 - 4 } & Elastic analysis & $\begin{array}{l}\text { Rigid-plastic } \\
\text { analysis }\end{array}$ & $\begin{array}{l}\text { Elastic-perfectly plastic } \\
\text { and elastoplastic analysis }\end{array}$ \\
\hline Continuous & Rigid & Full-strength & Rigid/full-strength \\
\hline Semi-continuous & Semi-rigid & Partial-strength & $\begin{array}{l}\text { Rigid/partial-strength } \\
\text { Semi-rigid/full-strength } \\
\text { Semi-rigid/partial-strength }\end{array}$ \\
\hline Simple & Pinned & Pinned & Pinned \\
\hline
\end{tabular}

Table 3. Simplified modelling of joints for frame analysis

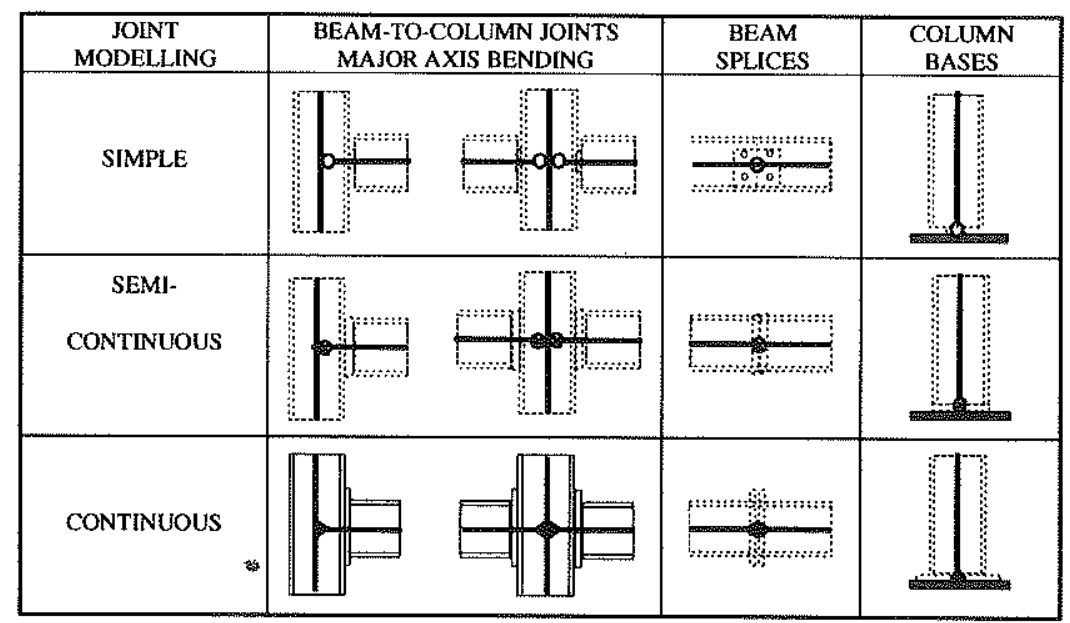

The interpretation to be given to these wordings depends on the type of frame analysis to be performed. In the case of an elastic global frame analysis, only the stiffness properties of the joint are relevant for the joint modelling. In the case of a 
rigid-plastic analysis, the main joint feature is the resistance. In all the other cases, both the stiffness and resistance properties govern the manner in which the joints should be modelled. These possibilities as well as their physical representation for frame analysis are illustrated in Table 2 and Table 3 respectively.

\subsection{JOINT CLASSIFICATION}

\subsubsection{Stiffness Classification}

The stiffness classification into rigid, semi-rigid and pinned joints is performed by comparing simply the design joint stiffness to two stiffness boundaries (Figure 3). For sake of simplicity, the stiffness boundaries are derived so as to allow a direct comparison with the initial design joint stiffness, whatever the type of joint idealisation that is used afterwards in the analysis.

\subsubsection{Strength Classification}

The strength classification simply consists of comparing the joint design moment resistance to "full-strength" and "pinned" boundaries (Figure 4).

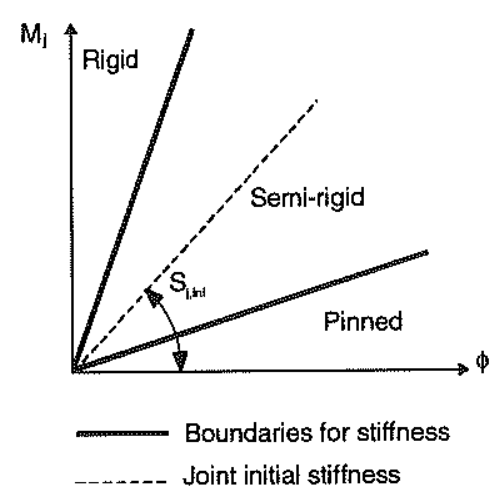

Figure 3. Stiffness classification boundaries

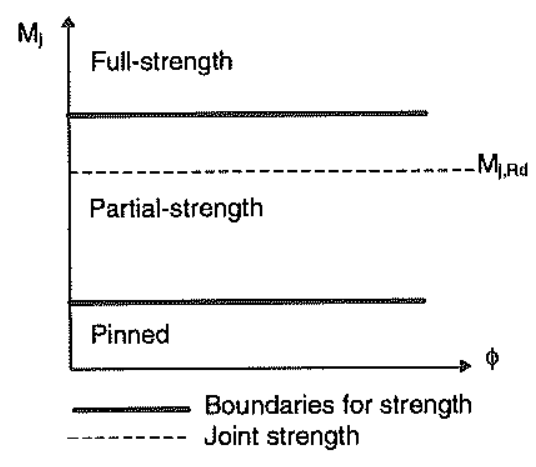

Figure 4. Strength classification boundaries

\subsubsection{Ductility Classes}

Experience and proper detailing result in so-called pinned joints which exhibit a sufficient rotation capacity to sustain the rotations imposed on them. For moment resisting joints the concept of ductility classes is introduced to deal with the question of rotation capacity.

Rather few studies have been devoted to the evaluation of the rotation capacity of joints. This is clearly illustrated in Eurocode 3 Revised Annex $\mathbf{J}$ where only a quite limited amount of information is given. Criteria should therefore be established to distinguish between "ductile", "semi-ductile" and "brittle" joints. Ductile joints are suitable for plastic frame analysis while brittle ones do not allow any redistribution of internal forces. The use of semi-ductile joints in a plastically designed frame can only result from a preliminary comparison between the available and required rotation capacities. 


\subsection{JOINT IDEALISATION}

The non-linear behaviour of the isolated flexural spring (see Table 3) which characterises the actual joint response for frame analysis does not lend itself towards everyday design practice. However the moment-rotation characteristic curve may be idealised without significant loss of accuracy. One of the most simple possible idealisations is the elastic-perfectly plastic relationship (Figure 5.a). This modelling has the advantage of being quite similar to that used for the modelling of member crosssections subject to bending (Figure 5.b).

The moment $M_{j, R d}$ that corresponds to the yield plateau is termed the design moment resistance in Eurocode 3. It may be considered as the pseudo-plastic moment resistance of the joint. Strain-hardening effects and possible membrane effects are henceforth neglected, which explains the difference in Figure 4.a between the actual $M-\phi$ characteristic and the yield plateau of the idealisation.

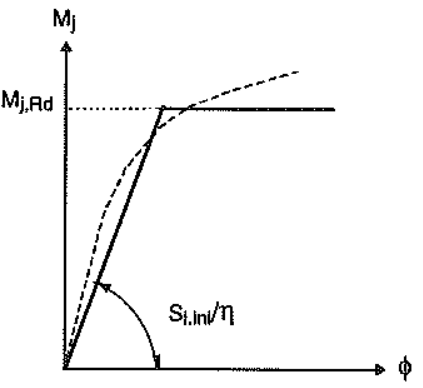

(a) Joint

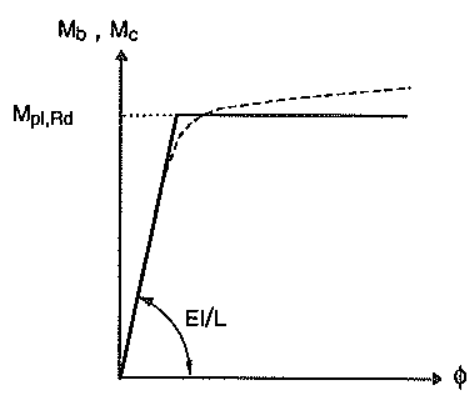

(b) Member

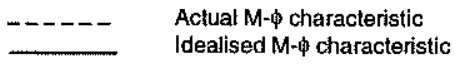

Figure 5. Bi-linearisation of moment-rotation curves

The value of the joint constant stiffness $S_{\mathrm{j} \text {.in }} / \eta$ is discussed in [5] and practical values are given in Eurocode 3 Revised Annex J. This coefficient results from the high nonlinearity of the joint $M$ - $\varphi$ curves in comparison to those of the members.

In fact there are different possible ways to idealise a joint $M-\phi$ characteristic. The choice of one of them is dependent upon the type of frame analysis which is contemplated:

- Elastic idealisation for an elastic analysis;

- Rigid-plastic idealisation for a rigid-plastic analysis;

- Non-linear idealisation for an elastic-plastic analysis. 


\section{The merits of the consistent approach for structural joints}

Both the Eurocode 3 requirements and the desire to model the behaviour of the structure in a more realistic way leads to the consideration of the semi-rigid behaviour when necessary.

Many designers would stop at that basic interpretation of the code and hence would be reluctant to confront the implied additional computational effort involved. Obviously a crude way to deal with this new burden will be for them to design joints that will actually continue to be classified as being either pinned or fully rigid. However such properties will have to be proven at the end of the design process and, in addition, such joints will certainly be found to be uneconomical in a number of situations.

It should be noted that the concept of rigid and pinned joints still exists in Eurocode 3. It is accepted that a joint which is almost rigid, or almost pinned, may still be considered as being truly rigid or truly pinned in the design process. How to judge whether a joint can be considered as rigid, semi-rigid or pinned depends on the comparison between the joint stiffness and the frame stiffness (see section 2.3).

The designer is strongly encouraged to go beyond this "all or nothing" attitude. Actually it is important to consider the benefits to be gained from the semi-rigid behaviour of joints. Those benefits can be brought in two ways :

$>$ The designer decides to continue with the practice of assuming -sometimes erroneously- that joints are either pinned or fully rigid. However, proper consideration has to be given to the influence that the actual behaviour of the joints has on the global behaviour of the structure, i.e. on the precision with which the distribution of forces and moments and the displacements have been determined. This may not prove to be easy when the joints are designed at a late stage in the design process since some iterations between global analysis and design checking may be required. Nevertheless, the following situations can be foreseen:

- So that a joint can be assumed to be rigid, it is common practice to introduce web stiffeners in the column. Eurocode 3 now provides the means to check whether such stiffeners are really necessary for the joint to be both rigid and have sufficient resistance. There are practical cases where they are not needed, thus permitting the adoption of a more economical joint design.

- When joints assumed to be pinned are later found to have fairly significant stiffness (i.e. to be semi-rigid), the designer may be in a position to reduce beam sizes. This is simply because the moments carried by the joints reduce the span moments in the beams.

The designer decides to give consideration, at the preliminary design stage, not only to the properties of the members but also to those of the joints. It may be shown [6] that this new approach is not at all incompatible with the sometimes customary separation of the design tasks between those who have the responsibility for conceiving the structure and carrying out the global analysis and those who have the responsibility for designing the joints. Indeed, both tasks are very often performed by different people, or indeed, by different companies, depending on national or local industrial habits. Adopting this novel early consideration of joints in the design process requires a good understanding of the balance between, on the one hand, the costs and the complexity of joints and, on the other hand, the 
optimisation of the structural behaviour and performance through the more accurate consideration of joint behaviour for the design as a whole. Two examples are given to illustrate this:

- It was mentioned previously that it is possible in some situations to eliminate column web stiffeners and therefore to reduce costs. Despite the reduction in its stiffness and, possibly, in its strength, the joint can still be considered to be rigid and be found to have sufficient strength. This is shown to be possible for industrial portal frames with rafter-to-column haunch joints in particular, but other cases can be envisaged.

- In a more general way, it is worthwhile to consider the effect of adjusting the joint stiffness so as to strike the best balance between the cost of the joints and the costs of the beams and the columns. For instance, for braced frames, the use of semi-rigid joints, which are not necessarily more costly than the pinned joints, leads to reducing the beam sizes. For unbraced frames, the use of less costly semi-rigid joints, instead of the rigid joints, leads to increased beam sizes and possibly column sizes.

Of course the task may seem a difficult one, and this is why a design handbook devoted to this new concept has been recently published [6]. The whole philosophy could be termed as "Because you must do it, take advantage of it". The designer has therefore the choice between a traditionalist attitude, where however something may often be gained, and an innovative attitude, where the most economical result [7] may best be sought.

\section{Practical applications of the Eurocode 3 design approach}

In the next pages a practical application is shown where one of the design opportunities described in the previous section is illustrated.

\subsection{BEAM-TO-COLUMN JOINT IN AN INDUSTRIAL PORTAL FRAME}

The beam-tomcolumn joint represented in Figure 6 is extracted from an industrial pitched-roof portal frame with an internal span of $20 \mathrm{~m}$ and a height of $7 \mathrm{~m}$. Its design has been initially achieved by a Belgian constructor on the basis of a traditional "rigid" approach.

In a second step, the evaluation of the mechanical properties of this joint has been performed by means of Eurocode 3 Revised Annex J; this gives:

- Initial rotational stiffness: $\mathrm{S}_{\mathrm{j} \text {.ini }}=114.971 \mathrm{kNm} / \mathrm{rad}$

- Moment resistance: $\quad \mathrm{M}_{\mathrm{Rd}}=281,6 \mathrm{kN}$

To fit with the designer's expectations, these two values have to be respectively higher than:

- The "rigid" boundary stiffness value (see 2.3.1) which, in this particular case [2], equals $85.627 \mathrm{kNm} / \mathrm{rad}$.

- The maximum bending moment transferred by the joint; this one results from a global frame analysis and it amounts $171 \mathrm{kNm}$. 
As the two design conditions are fulfilled, the joint design may be considered as fully satisfactory.
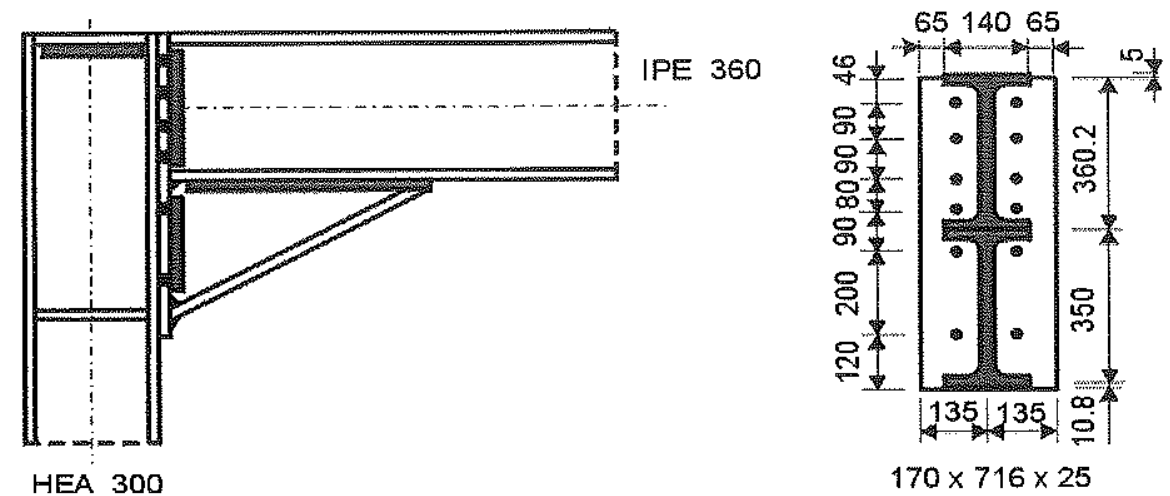

Figure 6. Geometry of the joint

Nowadays the stiffness verification requested by Revised Annex $J$ is not achieved and the joint is simply considered as "rigid" on the basis of the designer's experience. The extra work required by Eurocode 3 in order to demonstrate that the joint is rigid could therefore be considered as unnecessary.

But before discussing it further, the following statements has first to be made:

- The lake of knowledge in the field of joint design has led designers to systematically use transverse column stiffeners (in the compression and tension zones of the joints) in combination with thick end-plates when defining the geometry of rigid joints.

- Because of this "over-stiffening", the distribution of internal forces in the joints is of a linear type; this explains why an elastic approach has been traditionally followed by the designers to derive the bolt forces.

- In such a design procedure the bolts are the weak elements in the joints and no check of the plate elements (end-plates, column flanges, web flanges, ...) is required, what is the case in many national codes.

As it is seen this traditional design approach is fully consistent but often leads to over-designed joints and uneconomical configurations as the fabrication are highly dependent on the degree of stiffening. Furthermore the stiffening usually prevents from an easy erection on site. Finally the lack of ductility associated to the bolt failure is far from being satisfactory for what regards ductility aspects.

As an alternative Eurocode 3 Revised Annex $J$ proposes design rules where no predefined collapse mode is selected. The stiffness and resistance properties of all the constitutive components are integrated in the calculation. In other words, the actual properties of the joints are evaluated and it is up to the designer to modify the joint geometry according to his needs: select a ductile mode of collapse, make the joint more resistant, more stiff, ...

In the present case, the properties of the joint are beyond those required by the code (the resistance is larger than needed and a rotational stiffness of $85.627 \mathrm{kNm} / \mathrm{rad}$ is enough to ensure that the joint is rigid, as assumed in the frame analysis). Therefore a 
simplification of the joint geometry is likely to reduce the fabrication costs of the joints, and therefore of the whole structure.

In Table 4 three new joint configurations are considered:

- $\mathrm{N}^{\circ} 1$ : Initial geometry, but without the column transverse stiffener in the compression zone.

- $\mathrm{N}^{\circ}$ 2: Configuration $\mathrm{N}^{\circ} 1$, but without the column transverse stiffener in the tension zone.

- $\mathrm{N}^{\circ} 3$ : Configuration $\mathrm{N}^{\circ} 3$, but with three bolt-rows instead of four between the beam flanges.

For each of these configurations, the stiffness and resistance properties are listed and the result of the design checks is indicated.

In Table 5 the reduction of the fabrication costs for each of these configurations is given, the price reference being that of the initial stiffened configuration.

In conclusion it may be seen that, even for rigid joints, a quite significant benefit may be obtained by referring to the new design concept introduced in Eurocode 3. This one results from a better definition of the word "rigid" and the use of accurate calculation models for the prediction of the stiffness and resistance joint properties.

Table 4. Joint properties and design checks

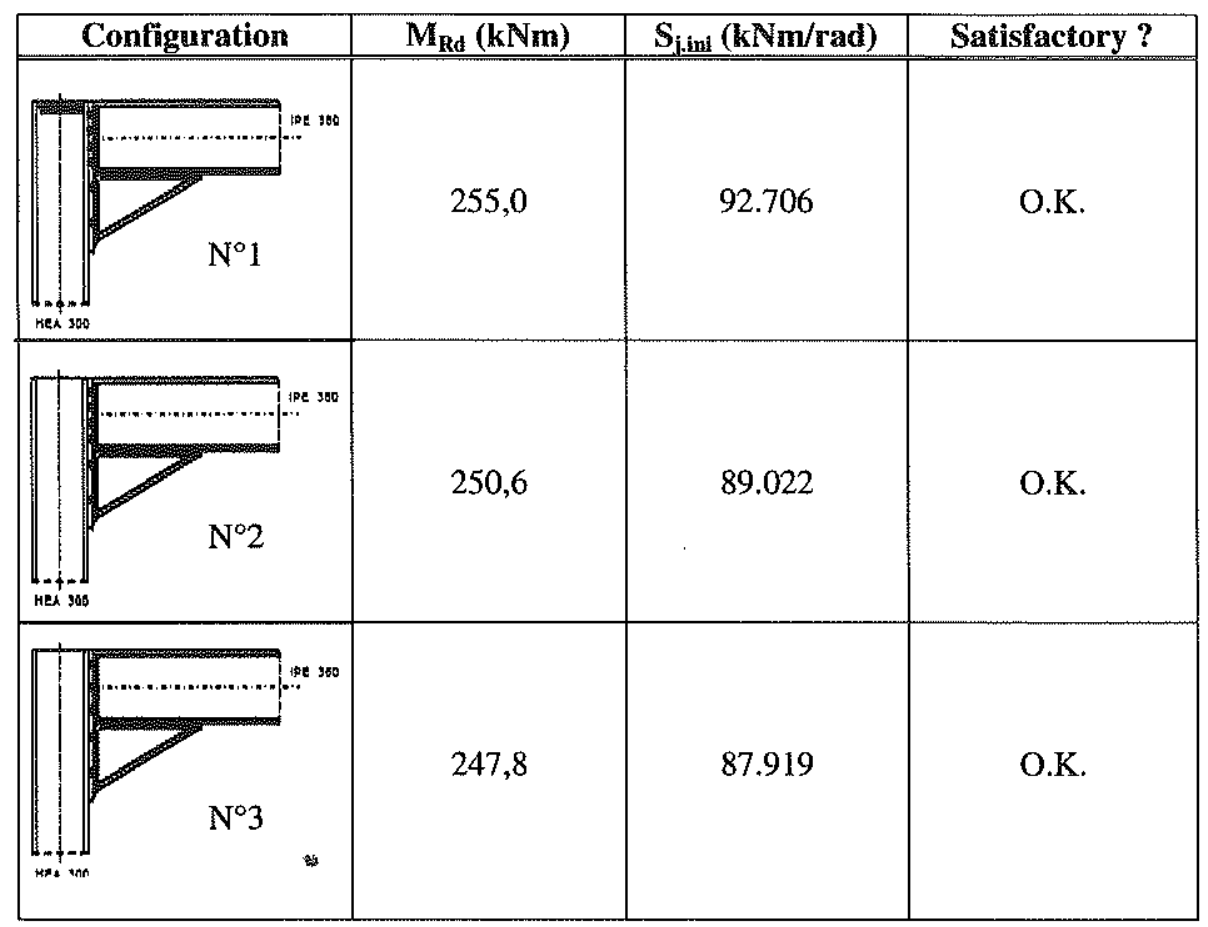


Table 5. Relative fabrication costs

\begin{tabular}{|c|c|}
\hline Joint configuration & Relative Iabrication cost \\
\hline Initial configuration & $100 \%$ \\
\hline Alternative $\mathrm{N}^{\circ} 1$ & $87 \%$ \\
\hline Alternative $\mathrm{N}^{\circ} 2$ & $73 \%$ \\
\hline Alternative $\mathrm{N}^{\circ} 3$ & $72 \%$ \\
\hline
\end{tabular}

\subsection{JOINT IN SWAY AND NON-SWAY BUILDING FRAMES}

The interested reader will find many others involving pinned, semi-rigid and rigid joints in [6].

\section{Conclusions}

A new consistent design approach for structural joints is now provided by Eurocode 3 . It is based on research works performed in the two last decades. For what concerns the joint characterisation, practical guidelines are now available for most of the steel joints (beam-to-column joints, beam splices, column bases, ...) in building frames made of I or I profiles and subjected to static loading. Its extension to composite joints has already been achieved and researches are in progress for a further application to other types of profiles and to other loading situations.

This new design procedure has been applied successfully in the last years to some different projects where substantial benefit resulting from a decrease of structural weight or a reduction of the fabrication and erection costs has been made possible. Such an example is described in the paper.

\section{References}

1. Eurocode 3 (1992), Design of Steel Structures. Part 1.1: General Rules and Rules for Buildings, European Prestandard -- ENV 1993-1-1.

2. Revised Annex $\mathrm{J}$ of Eurocode 3 (1998), Joints in building frames, European Prestandard ENV 1993-1-1:1992/A2, CEN, Bruxelles, Belgium.

3. COST C1 (1999), Column bases in steel building frames, COST C1 report edited by $\mathrm{K}$. Weynand, European Commission, Bruxelles, Luxembourg.

4. COST C1 (1999), Composite steel-concrete joints in frames for buildings: design provisions, COST $\mathrm{Cl}$ report edited by D. Anderson, European Commission, Bruxelles, Luxembourg.

5. Jaspart, J.P. (1997), Recent advances in the field of steel joints - Column bases and further configurations for beam-to-column joints and beam splices, Professorship Thesis, Department MSM, University of Liège, Belgium. 
6. Maquoi, R \& Chabrolin, B. (1998), Frame design including joint behaviour, ECSC Report 18563, Office for Official Publications of the European Communities, Luxembourg.

7. Weynand, K (1997), Sicherheits- und Witschaftlichkeits-untersuchungen zur Anwendung nachgiebiger Anschliusse im Stahlbau, Heft 35, Shaker Verlag, Aachen, Germany.

8. Vandegans, D. (1996), Use of the threaded studs in joints between I-beams and RHS columns, Proceedings of the Istanbul Colloquium on Semi-Rigid Connections held on September 25-27, pp. 53-62, IABSE, Zürich, Switzerland. 